\title{
A Calculational model FOR CONDENSATION OF WATER VAPOR DURING AN UNDERGROUND NUCLEAR DETONATION
}

Richard J. Knox

October 1, 1975

Prepared for U.S. Energy Fesearch \& Development Administration under contract No. W-7405-Eng-4B
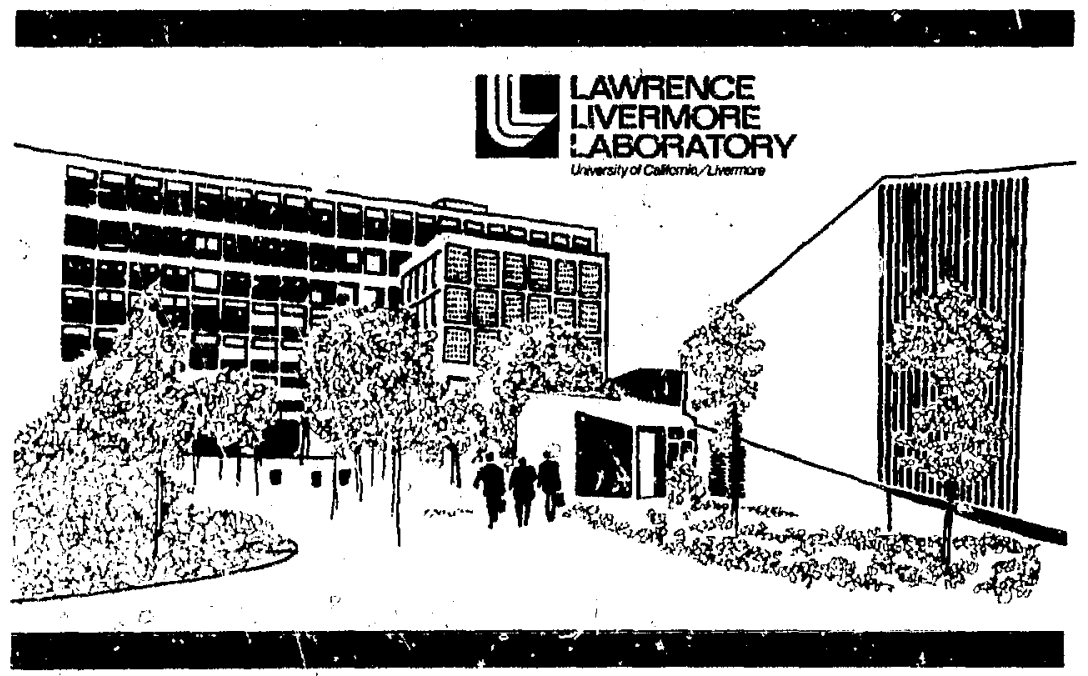
NOTICE

"Thls report was prepared a an accusnt of work spontored by the United Stutes Government. Naither the United States nx the United States E. $r$ g Resauch \& Drwolopment Administration, nor eny of the moloyes, nor eny. of thet contractors, subcontracton, or theis employees, makes uny werranty, expreas of limpliad, or exumel ony bitel ilabulty of reponability for the securecy. complatenes of usefulnes of any information, coperatue produet as process vinclosed, $7 \mathrm{r}$ isprestall that its we would not bifinte privatulyowned tighta"

Printed in the United States of America Avaílable from.

National Technical Information Service U.S. Department of Commerce 5285 Fort Royal Road

Springfield, Virginia 22151

Price: Printed Copy $\$$ *; Microfiche $\$ 2.25$

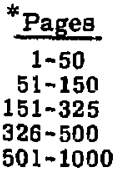

NTIS

Selling Price

$\$ 4.00$

$\$ 5.45$

$\$ 7.60$

$\$ 10.60$

$\$ 13.60$ 
Distribution category

UC-11

\section{노 \\ LAMRENCE LNEFMORE LABORATORY

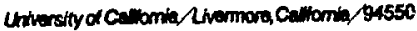

\section{UCRL-51901 \\ A CALCULATIONAL MODEL FOR CONDENSATION OF WATER VAPOR DURING AN UNDERGROUND NUCLEAR DETONATION}

Richard J. Knox

Ms. date: September 10, 1975

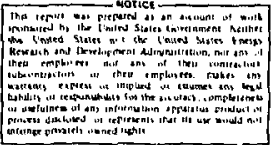

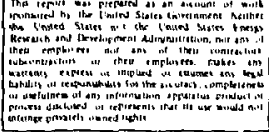




\section{Contents}

Abstract . . . . . . . . . . . . . . . . . . . . . . 1

The Conventional Cavity Pressure-Temperature History Formulation . . . . . 1

Improvenents to the Cavity-History Formulation . . . . . . . . . . . . 5

Temperature and Pressure at Inctpient Condensation . . . . . . . . . . . 13

Calculation of the Time of Inciplent Condenation . . . . . . . . . 16

Calculation of TIme Duration and Heat Lose During Condensetion . . . , , 19

Calculation of the Pressure-Temperature History During Condensation , . 23

Conclugion .... . . . . . . . . . . . . . . . . . . . 28

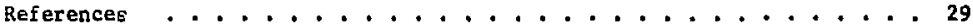

Appendix: Derivation of the Newtonian Cooling Equation ......... 30 


\title{
A CALCULATIONAL MODEL FOR CONDENSATION OF WATER VAPOR DURING AN UNDERGROUND NUCLEAR DETONATION
}

\begin{abstract}
An empirally derived mathematical

to describe the phenomena. The model has been developed to calculate calculaced pressure-nistory during the pressure and temperature history during condensation of water vapor in an underground-nuclear-explosion cavity. The condensation procesa 18 non-1sothermal. Use has been made of the Clapeyron-Claustus equation as a basis for development of the model. Analytic fits to the vapor pressure and the latent heat of vaporization for saturated-water vapor, together with an estimated value for the heattransfer coefficient, have been used condensation has beed determined to be exponential, with a time constant somewhat less than that observed during the cooling of the superhested ateam from the exploston. The behavior of the calculated condensationpressure compares well with the observed-pressure record (until just prior to cavity collapse) for a particular nuclear-detonation event for which we have data.
\end{abstract}

\section{The Conventional Cavity Pressure-Temperature History Formulation}

Olsen ${ }^{1}$ has devised a simplifted rodel for cavity cooling based on the time-dependen: Newtonian cooling process. Upon termination of cavity growth, the vaporized rock must condense in a very ahort time (on the order of a few tenths of seconds) in contrast with the longer term cooling (tens of minutes) of the water vapor. The longer term cooling of this superheated steam has been modeled by $01 \operatorname{sen}^{1}$ using the Newtonfan decav algortchm (see Appendix) given by:

$$
\frac{T-T_{\infty}}{T_{0}-T_{\infty}}=e^{-\left(h A / c v^{n}\right) t},
$$

where

$$
\begin{aligned}
& t=t \text { ims in minutes, } \\
& T=\text { temperature at time } t \text { in } \\
& \text { kelvins. Also, } r=T_{0} \text { at } \\
& t=0 \text { (derived from } \\
& T_{0}=\frac{P_{0} V}{n R}, \text { whers } P_{0}= \\
& \text { overburden pressure) and }
\end{aligned}
$$




$$
\begin{aligned}
& T=T_{\infty} \text { at } t=\infty \text { Cambient } \\
& \text { tomperature of cavity wall } \\
& \text { is assumed constant). } \\
& \text { h - surface heat transfer } \\
& \text { coeffictent }\left(\mathrm{cal} / \mathrm{cm}^{2}\right. \text {. } \\
& \text { sec-K), } \\
& \text { A - surface area of cavity in } \mathrm{cm}^{2} \\
& \text { R - } 0.08314 \text { 11ter - bar/mole - K } \\
& \text { (gas constant) } \\
& \mathrm{n} \text { - total moles of water vapor } \\
& V \text { - cavity volume in } 11 \text { ters } \\
& c_{y}=\text { molar heat capacity of the } \\
& \text { steam at constant volume } \\
& \text { (cal/mole.K) }
\end{aligned}
$$

Assuming that the behavior of the steam follows the Ideal gas law, the. pressure is derivable from the axpression

$$
P=\frac{n R T}{v} \text {. }
$$

0loen was able to achleve a good fit to the pressure history for a particular underground nuclear event for which the following values were used:

$$
\begin{aligned}
& p=1.9 \mathrm{~g} / \mathrm{cm}^{3} \text { - overburdon density } \\
& h=0.012 \mathrm{cal} / \mathrm{cm}^{2} \cdot \mathrm{sec}^{2} \mathrm{~K} \\
& Y=6.5 \text { kilotons = device } y t a l d \\
& \text { d - } 240 \text { meters - depth of burlal } \\
& c_{v}=6.5 \text { cel/mole } \cdot \dot{K} \\
& W=0.12 \text { welght fraction of water } \\
& \text { at the shot point. }
\end{aligned}
$$

It to for this sane event that an att. mpt is made in chis paper to also calculate the condensation-pressure history. Initially, olisen used both a fixed value: for $c_{v}\left(1 . e ., c_{v}=\right.$ $6.5 \mathrm{cal}$, (nola $\cdot K$ ), which was treated as the average over the entire temperacure range, and a cavity radius formula independent of the In oitu water content, However, adjusting the value of the heat transfer coefficient ${ }^{*}$ ( $1 . e ., h=0.012$ cal $/ \mathrm{cm}^{2}$-sec.K), produces a good $\mathrm{f} 1 \mathrm{t}$ between the calculated and observed pressurn data until shortly before cavity collapse. The result of that fit is dispicyed in F1g. 1. Figure 2 depicts the correaponding calculated pressure vs temperalure curve. 0loen ${ }^{2}$ later macia a study of pressure decay in several underground events using a modified form of the Newtonian equation in order to accounc for the effect of rock strength on the Initial pressure. For this purpose, an "excess pressure" coeffictent was implemented, permitting calculated cavicy pressures to exceed overburden pressure. In several cases, one or more parameters in the equation had to be altered to obtain a consistent i1t. However, the value of $h=0.012$ $\mathrm{cal} / \mathrm{cm}^{2} \cdot \mathrm{sec} \cdot \mathrm{K}$ seemed to be about the beat value for the transfer coefficient.

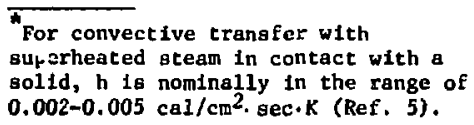




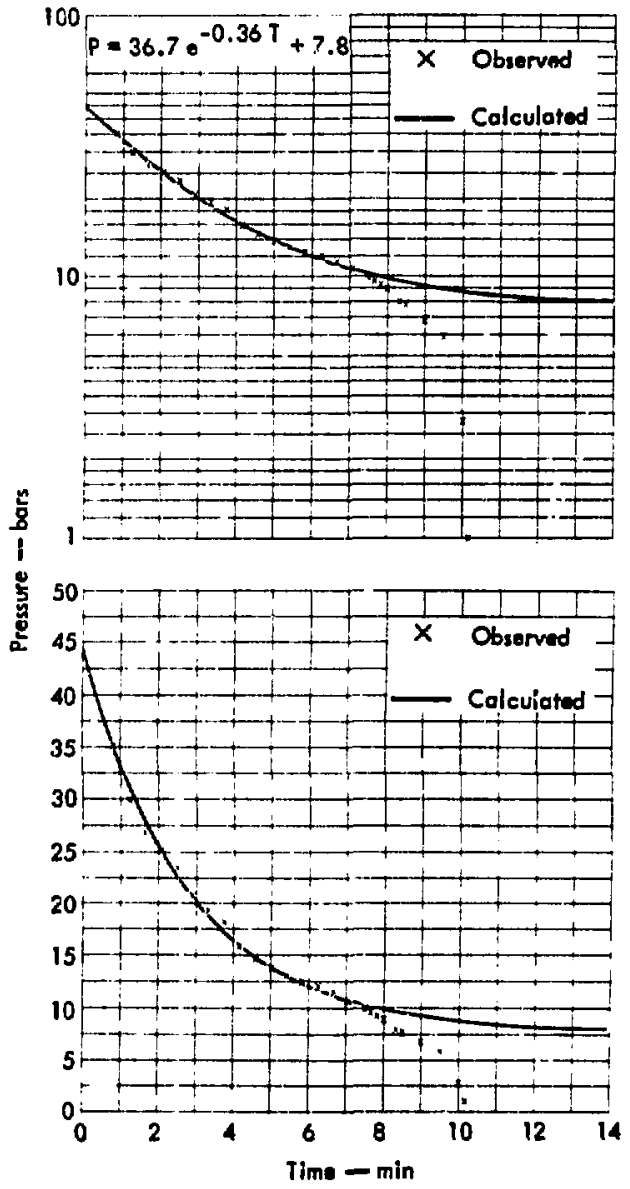

F18. 1. Oleen's exponential fit to the obaerved preseure decay, dioplayed IInearly and geat-logerithmically. Both $c_{v}$ and $h$ are constant $\left(c_{y}-6.5 \mathrm{cal} / \mathrm{mole}\right.$ and $\left.\mathrm{h}-0.012 \mathrm{cal} / \mathrm{cm}^{2} \cdot \mathrm{Bec}^{\mathrm{K}} \mathrm{K}\right)$. 


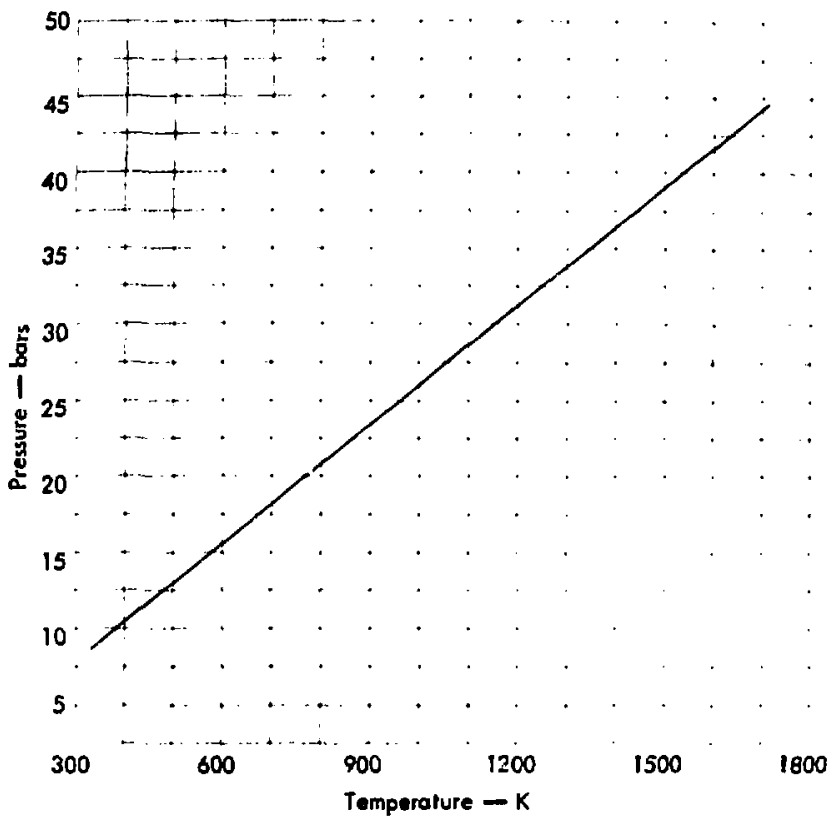

E1g. 2. Preseure vo cemperature curve resulting fron the ideal-gas-law asaumption for the calculaced fit of Fig. 1. 


\section{Improvements to the Cavity-History Formulation}

A code (called DCAVSTM ${ }^{3}$ ) has recently been written for the Hewlett-Packard HP-9821A computer and for Lawrence Livermore Laboratory's (LLL) Clic-7600 that calculatea a cavily's entire pressure-temperature history through condensation. This code employs the original Newtontan cooling calculation with minor Improvements and includes the lacetime development of the vapor condensation phase. The DCAVSTM code calculates the terperature and pressure historles prlor to condensation using a modified Newtontan equation. Also, the code includes:

- A comperature-dependent $c_{v}$

- A ravity radlus with dependence of water content

- A temperature-dependent heattransfer coeffictent.

Olsen's latest technique ${ }^{2}$ uses HIggens and Butkovich's ${ }^{4}$ revised cavity-radius $\left(R_{c}\right)$ formula which Includes the effects of water content,

\footnotetext{
* Reference to a company or product name does not 1mply approval or recommendation of the product by the University of California or the U.S. Energy Research \& Development Adminiatration to the exclusion of others that may be suttable.
}

1.e.,

$$
R_{c}=\frac{100 \mathrm{Y}^{1 / 3}}{[\rho d]^{\alpha}}
$$

where

$$
\begin{aligned}
R_{c} & =\text { cavity radius expreased in } \\
& \text { meters } \\
Y & =\text { yleld in kilotons } \\
\rho & =\text { density In gram/ } \mathrm{cm}^{3} \\
d & =\text { depth of burial in meters }
\end{aligned}
$$

and

$$
\begin{aligned}
\alpha= & 0.3262-0.3326 w+0.7857 w^{2}- \\
& 0.9778 w^{3} .
\end{aligned}
$$

The total moles of water in the ca: $1^{+} y$ $\left(n_{0}\right)$ Is given by

$$
n_{0}=\frac{W}{18}\left(7 \times 10^{8}\right)
$$

assuming $7 \times 10^{8}$ grams of rock is vaportzed and melted by the detonation. 5 The cavity growth 18 assumed to terainate when the $\mathrm{g}^{19}$ pressure is equal to or slightly greater than the overburden pressure ( $P_{0}$, In bars) which is given by:

$$
P_{0}=1 \times 10^{-4} \rho g d
$$

where $8-980 \mathrm{~cm} / \mathrm{sec}^{2}$ (acceleration of gravity). The expression for $P_{0}$ assumes an "excess overburden" coefflctent of unity.

In terms of the units mentioned, the inftial temperature $T_{0}$ is derivable using Eqs, 2 through 5. 


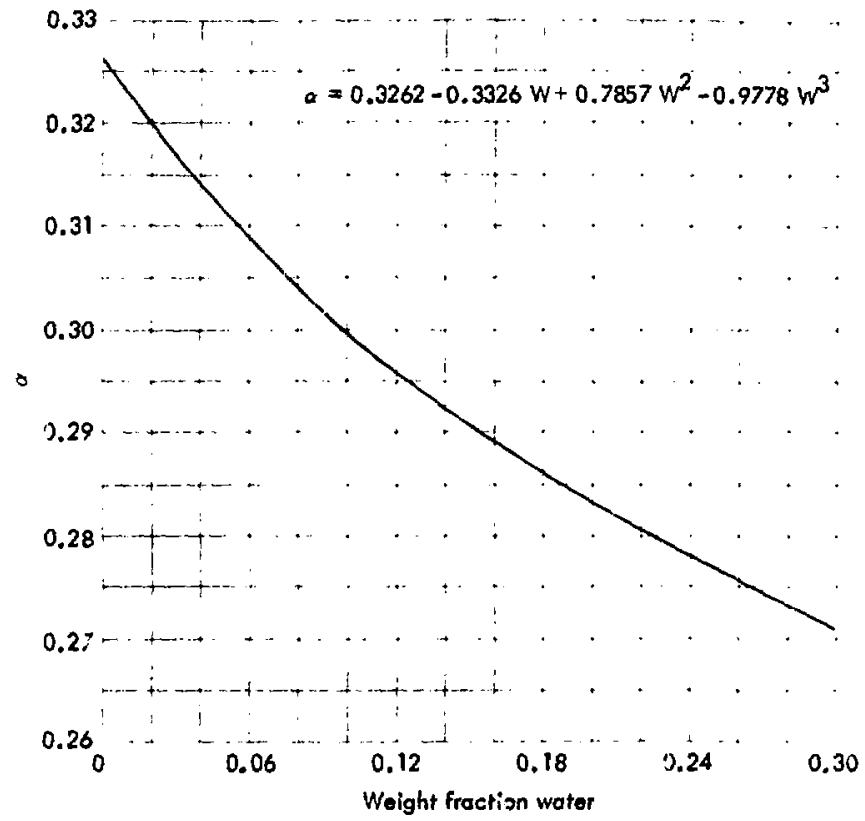

F1g. 3. Smoothed function representing the dapendence of the empirical parameter, $\alpha$, p.s a function of welght-fraction water. See Butkovich's cavity-radiug formula.5

That is,

$$
T_{0}=1.2955 \times 10^{-7} \frac{\rho g d R_{c}^{3}}{W Y} .
$$

and for

$$
T_{\infty}=300 \mathrm{~K},
$$

the temperature expression takes the form

$$
\begin{gathered}
T=\left(t_{0}-T_{\infty}\right) e^{-1938,81 \mathrm{ht} /\left(\mathrm{c}_{\mathrm{v}}\right.} \\
\left.w \mathrm{~W}^{1 / 3}[\rho \mathrm{d}]^{2 \alpha}\right)+\mathrm{r}_{\infty}
\end{gathered}
$$

or

$$
T=K_{1} e^{-k_{2} t}+300,
$$

where the coeffictents of the above equation are

$$
\begin{aligned}
k_{1}= & 1.2955 \times 10^{-3} \\
& \frac{\rho g R_{c}^{3}}{W Y}-300
\end{aligned}
$$


and

$$
\begin{gathered}
k_{2}=1938.81 h /(c) \\
\left.w Y^{1 / 3}[\rho d]^{2 u}\right) .
\end{gathered}
$$

The pressure can then ba derfved by assuning the ideal gas law,

$$
P=\left(\frac{n_{0} R}{v}\right) T \text {. }
$$

where

$$
\begin{aligned}
R= & 0.08314 \text { Ifter } \cdot \mathrm{bar} / \text { mole } \cdot K \\
& \text { (ás constant) }
\end{aligned}
$$

and

$$
v \text { = cavity volume in Itters; }
$$

or

$$
P=\left(i 71.9 \frac{\mathrm{WY}}{\mathrm{R}_{\mathrm{c}}^{3}}\right) T=K_{3} T \text {. }
$$

Using Eq. (B) as the expression for temperature ve obtain

$$
\begin{aligned}
p & =k_{3}\left(k_{1} e^{-k_{2} t}+3 n 0\right) \\
& =\Lambda_{1} e^{-k_{2} t}+B_{1} .
\end{aligned}
$$

$0161^{2}$ implemented $c_{v}$ as a function of vapur teinperature according to the empirical equation:

$$
\begin{aligned}
c_{v}= & 5.913-54.32 / \mathrm{T}+8.009 \times \\
& 10^{-4} \mathrm{~T}+6.404 \times 10^{-7} \mathrm{~T}^{2}
\end{aligned}
$$

(See Fige. 4 and 5). Th1 had the effect of decreasing the pressure decay at early times and increasing it at late times. Although the overa11 deviation was not major, Introduction of a varlable $c_{v}$ did not lmprove the fitting properties (see FIB. 6) for comparison with measured data. However, Olsen had reason to belleve an Improvement was evident in calculations at high yields and considerable depth of burial, but was not abie to make a comparisor. of results for the case of a varlable cv with any "observed" data. Since there was probably more uncertainty in the value of the heattransfer ccefficient and in the determination of the water content (1) in the cavity region during this era than in other geologic quantities, we attimpted several fits to the observed pressure data by irdependent variation of the water cortent $(W \pm 47)$ and heat transfer coeffictent $(h \pm 50 \%)$, aji of which proved to be unsuccessful. However, an improved fit was accomplished by introducing a simple dependence for the heat transfer coefficient upon water vapor temparatures (see Fig. 7):

$$
h=h_{0}(1+B T)
$$

where

$$
h_{0}=0.0068 \mathrm{col} / \mathrm{cm}^{2} \cdot \sec \cdot K^{-1},
$$

and

$$
B=6.087 \times 10^{-4} \mathrm{k}^{-1} \text {. }
$$

The assoclated temperature history ig given In Fig. $B$. 


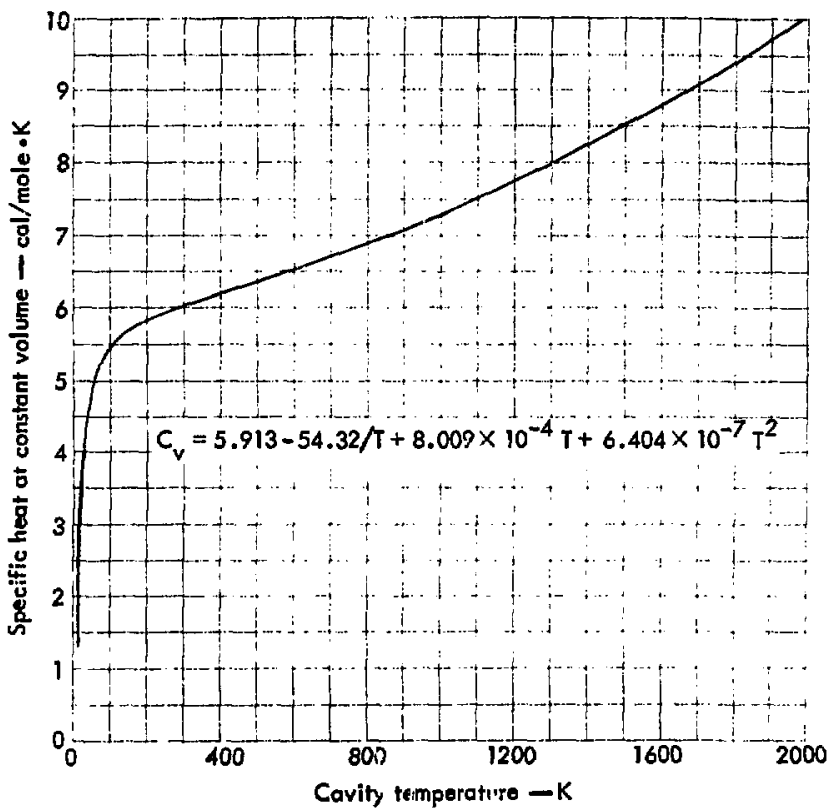

Fis. 4. Empirical fit to the specific heat of superheated steam (lowtemperature range). 


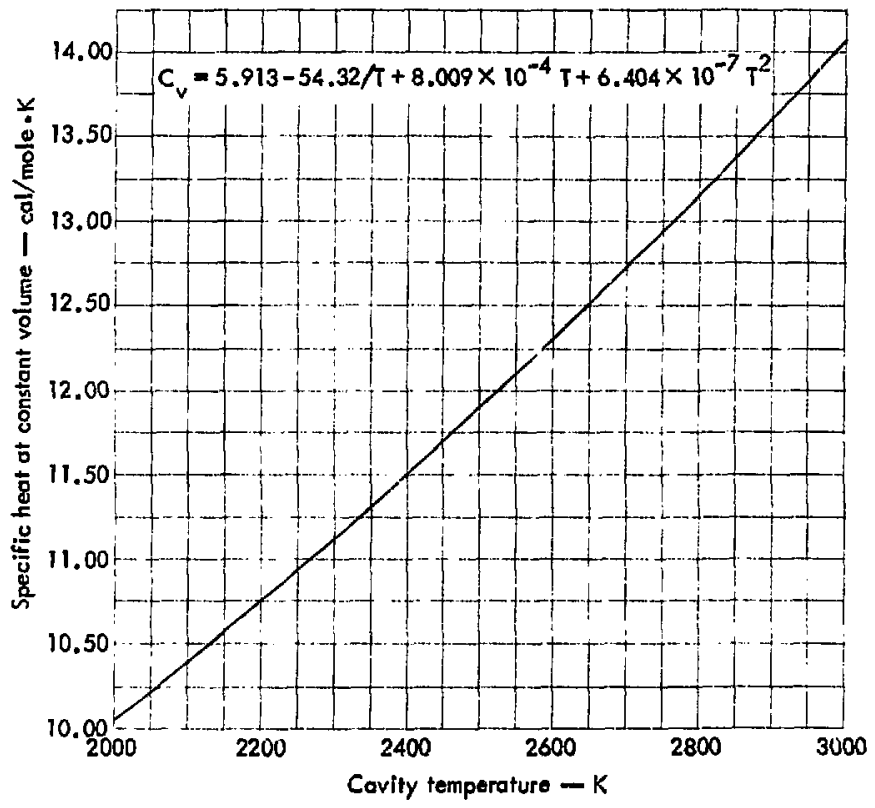

Fig. 5. Empirical fit to the apecific heat of superheated steam (high temperature range). 


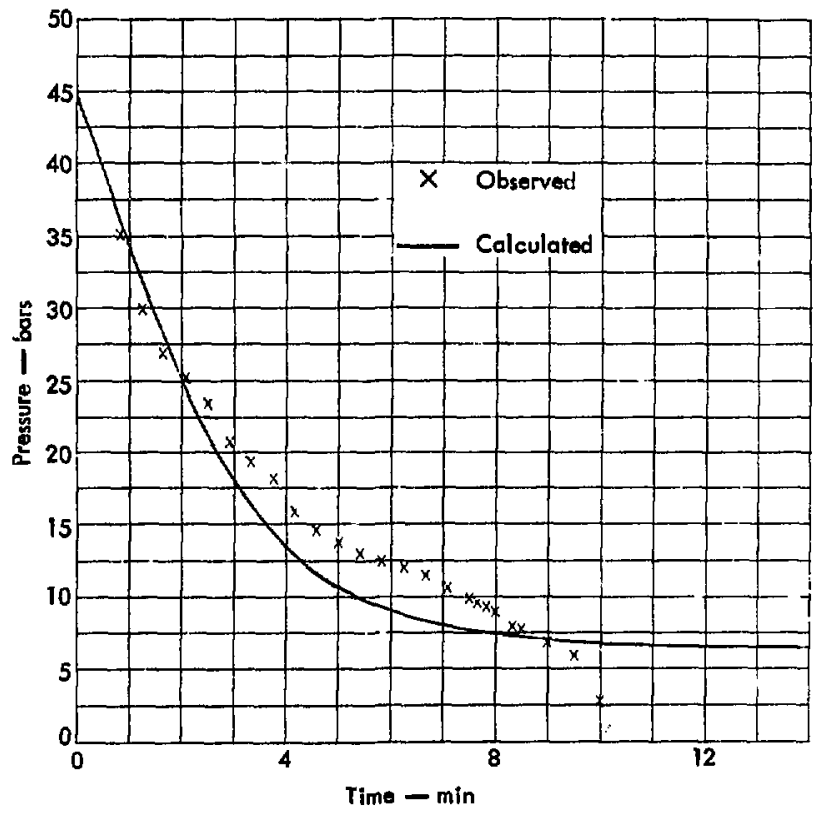

Fig. 6. Calculated pressure decay for the example data with a constant $h-0.012 \mathrm{cal} / \mathrm{cm}^{2} \cdot \mathrm{sec}^{\mathrm{K}} \mathrm{K}$ ahowing the fallure of a temperature-dependent $c_{y}$ alone to Improve fitting properties. This fit also used the waterdependene cavicy-radius formula. 


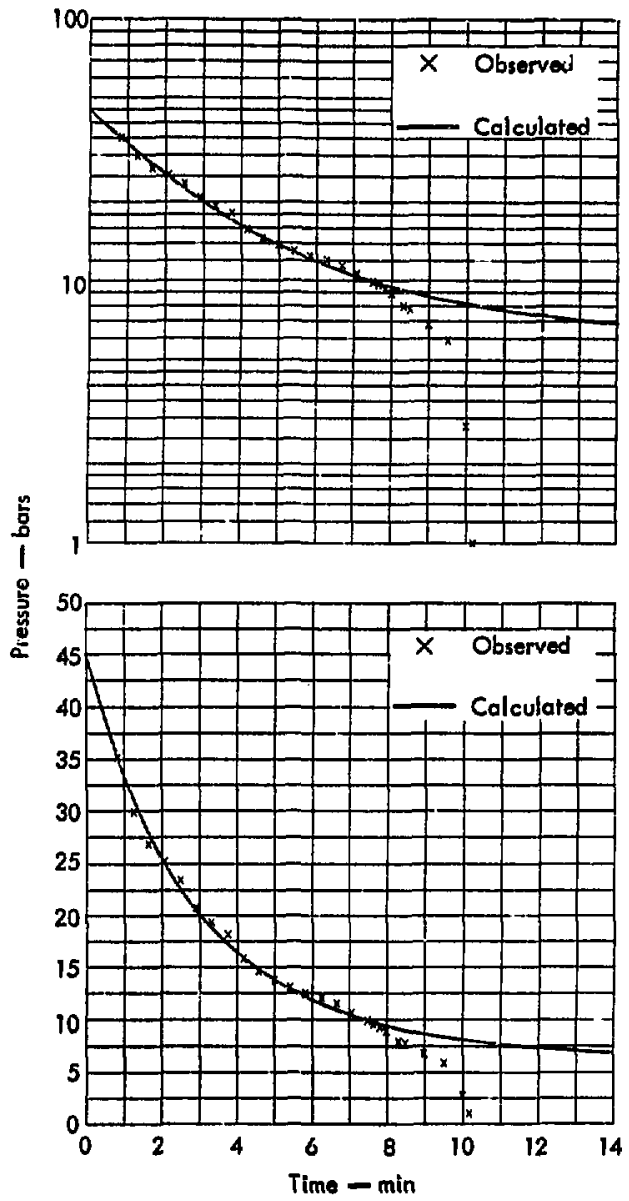

F18. 7. Improved calculated fit to the observed decay displayed 11nearly and semilogertthmically. Fit ues the same conditions as F18. 6 but includes a tomperature-dependent heat-trangfer coeffictent. 


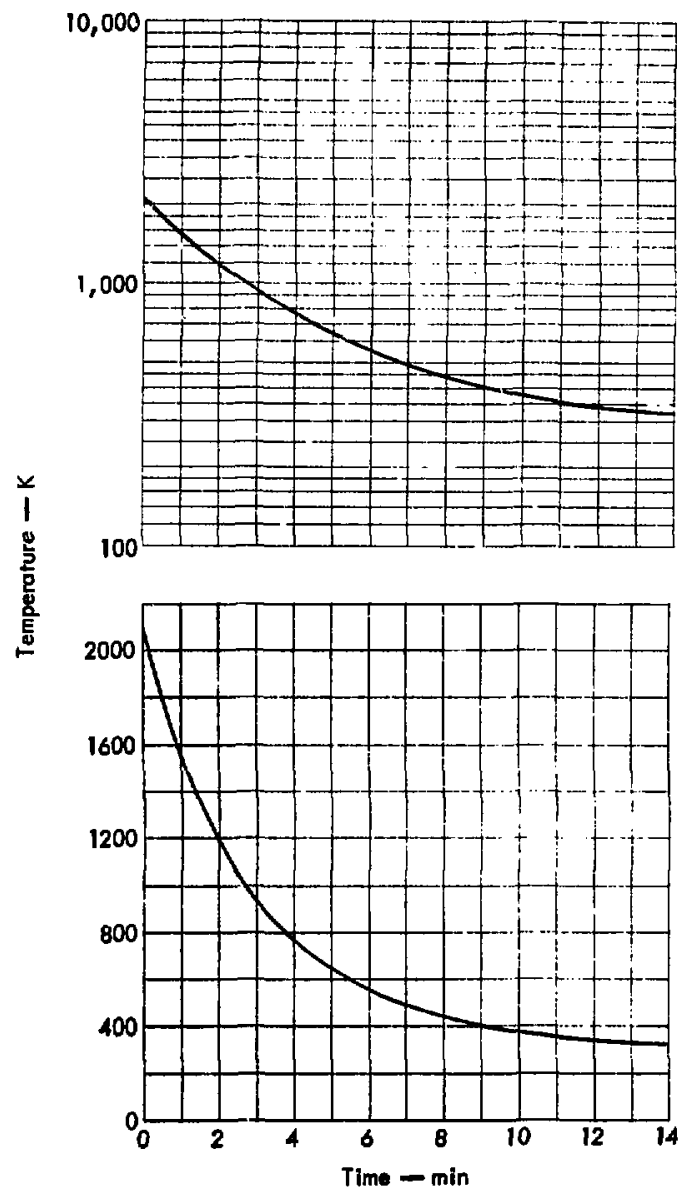

F1g. 8. Calculated temperature curves uatgg the Improved fitting parawelers of F18. 7 . 


\section{Temperature and Pressure at Incipient Condensation}

An analytic description of tabular vapur pressure data for water Is essential for the calculation of both the temperature and pressure at the instant condensation begins. From tileoretical considerations, it may be shown that the vapor pressure of water can be approximatly fitted to a simple exponential equation of the form

$$
P=c_{1} e^{-c_{2} / T} \text {. }
$$

Ustag tabular vapor pressure data, the constants $c_{1}$ and $c_{2}$ take the values of

$$
\begin{aligned}
c_{1}= & 3.32431 \times 10^{5} \\
& \text { (for P 1I bars) }
\end{aligned}
$$

and

$$
c_{2}=4.73976 \times 10^{3} .
$$

The fit using these constants is shown in Fig. 9.

Condensation begins at the point (P*, T*) where the cavity pressure decay with temperature intersects the vapor-pressule (V-P) curve for water. That Is,

$$
\begin{aligned}
& P_{\text {caviry }}=\frac{n_{0} R}{V} T=k_{3} T- \\
& P_{\text {vapor }}=c_{1} e^{-c_{2} / T} \\
& \text { preseure }
\end{aligned}
$$

where $K_{3}$ was defined in the previous section to be

$$
K_{3}=771.9 \frac{\sqrt{Y}}{R_{c}^{3}}
$$

The quantity $K_{3}$ is known and the constants $c_{1}$ and $c_{2}$ are determined from the functional fit; however, $k_{3} T=c_{1} e^{-c_{2} / T}$ is not direct $1 y$ solvable for $T$. Analytically, it requires a special technique because of the non-1ineerity. We have developed a recursive method called the "ruethod of appraaching tangenta". It gives rapid convergence in a very few Iterationg and may be done without the ald of computers.

Referring to $\mathrm{Fig}$. 10 for Identification of the subscripted varlables $\left(P_{1}, T_{1} ; P_{2}, T_{2} ;\right.$ etc. $)$, a tangent to the $\mathrm{V}-\mathrm{P}$ curve can be drawn through the critical point (not shown In $\mathrm{FIg}, 10$ ). The cavity pressute decay curve intersects this tangent at a coordinate in $P-T$ space $\left(P_{1}, T\right)$. The equation of this tangent 11ne (called "tangent IIne No. 1 " In Fig. 10) is given by:

$$
P=P_{c}-\left(\frac{d P}{d T}\right)_{T_{c}}\left(T-T_{c}\right)
$$

where

$$
\begin{aligned}
T_{c}= & 647.18 \mathrm{~K} \text { (critical } \\
& \text { temperature), } \\
P_{c}= & 220.61 \text { bars (critical } \\
& \text { premaure). }
\end{aligned}
$$




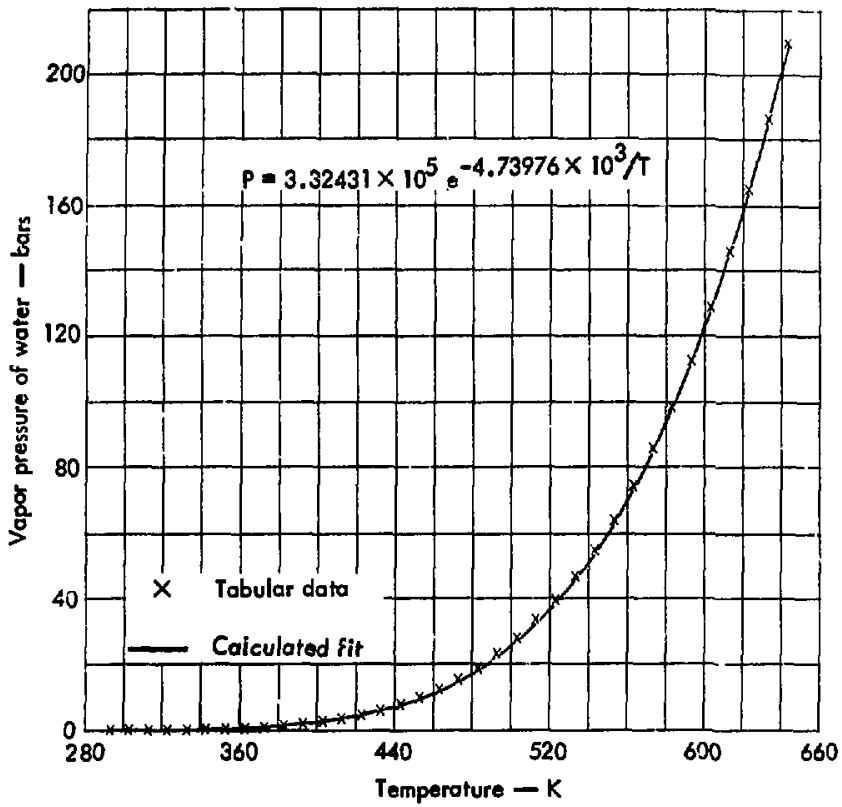

F18. 9. Fit of $P=3.32431 \times 10^{5} \mathrm{e}^{-4.73976 \times 10^{3} / \mathrm{T}}$ to tebular vapor pressure data of water.

and the slope of the (V-P) curve is determined to be

$$
\left(\frac{\mathrm{dP}}{\mathrm{dT}}\right)_{T_{c}}=\frac{c_{1} c_{2}}{T_{c}^{2}} e^{-c_{2} / T_{c}}=A .
$$

At the Intersection of this tangent Ine with the decayli: : : ltympressure curve, we obtain the $t:=$ yectature

$$
T=\frac{P_{1}}{K_{3}} \text {. }
$$

The corresponding pressure at that intersection is derivable using Eqs. 19, 20 and $21,8 \mathrm{~s}$ follows:

$$
P_{1}=P=\frac{P_{c}-A T_{c}}{\left(1-\frac{A}{K_{3}}\right)} \text {. }
$$

If this pressure value $P_{I}$ is translated horizontally to the $V-P$ curve, it corresponda to a temperature $\left(T_{1}\right)$ at that intersection. Whereupon, making 


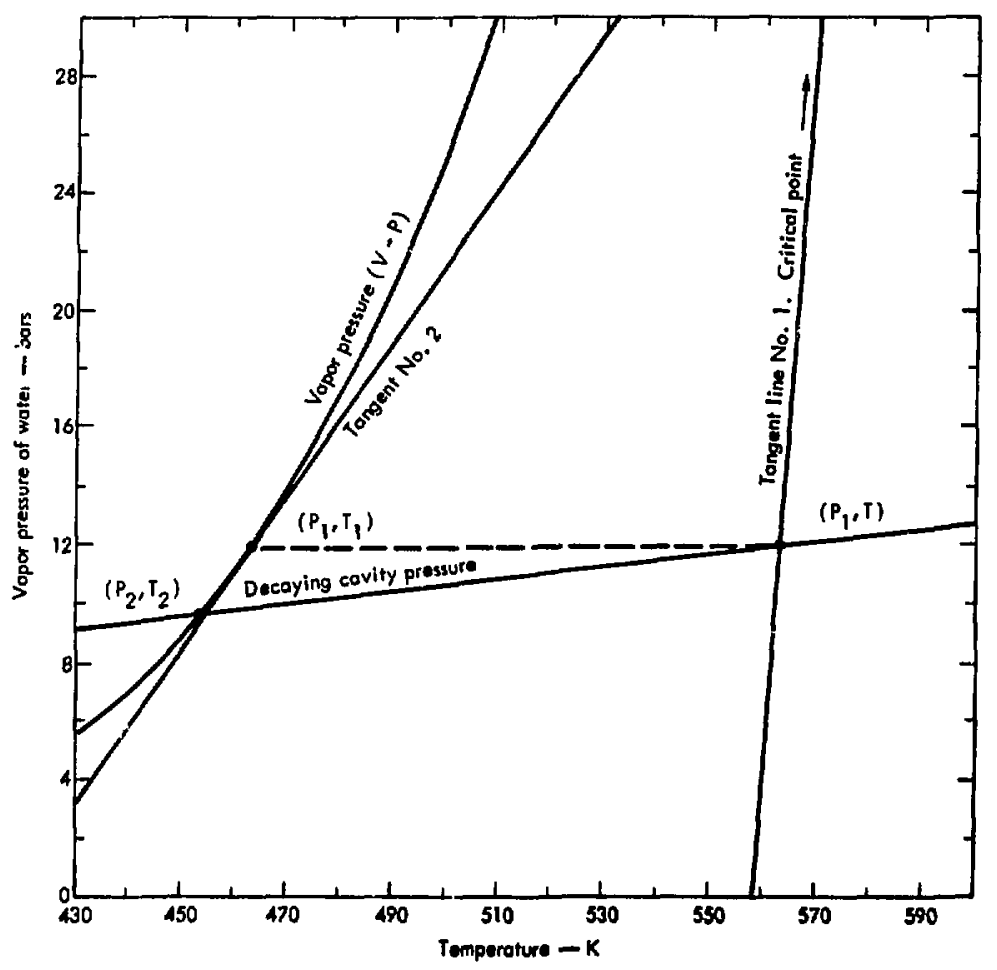

F18. 10. Illustration of recursive calculational technique by which the intersection of the 1deal-gas function and the vapor preseure for water 1s datermined, 
use of the V-P equation $[\mathrm{Eq},(17)]$,

$$
T_{1}=\frac{c_{2}}{\ln _{P_{1}}} \text {. }
$$

$T_{1}$ is thus the first estimate of the Inciplent cendensation temperature.

The next estimate is made, sinilarly, by construction of a second tangent paseing through point $\left(P_{1}, T_{1}\right)$ and repcating Eqs. (20, 22 and 23) where, in equation (20), we subetitute $T_{1}$ for $T_{c}$ and calculate a new A. This value of A together with $T_{1}$ and $P_{1}$ (which to now being subatituted for $P_{c}$ ) are then used in the $\mathrm{right}$ member of $\mathrm{Eq},(22)$.

A new pressure, $P_{2}$, is then calculated with Eq. (22). ThIs presstire $\left(P_{2}\right)$ 1s used in Eq. (23) to arrive at " second estimate $\left(T_{2}\right)$. Figure 10 thus indicateg graphically how this solution converges. A calculation of $T$ and $P$ at the beginning of condensation 18 given In the following section for the example data.

\section{Calculation of the TIme of Incipient Condensation}

The time at which condencetion begin is calculable fron

where

$$
P=A_{1} e^{-K_{2} t}+B_{1}
$$

$$
A_{1}=K_{3} K_{1}
$$

and

$$
B_{1}=T_{\infty} K_{3}-300 K_{3}
$$

(Average values of $c_{v}=6.3$ and $h=$ 0.0085 were celected to calculate $R_{2}$ during the condenention phese,) Therefore.

$$
A_{1} e^{-K_{2} t}=P-B_{1}
$$

whtch leade to:

$$
c=-\frac{1}{K_{2}} \ln \frac{A_{1}}{F-E_{1}}
$$

where $t$ is expressed in minutes. olsen'a original fit to the pressure decay was:

$$
P=36.7 e^{-0.36 t}+7.8
$$

from which

$$
\begin{aligned}
& A_{1}=36.7 . \\
& k_{2}=0.36,
\end{aligned}
$$$$
\text { and } B_{1}=7.8 \text {. }
$$

lising the method described, the pressure at condensation was determined from the intersection of Olmen's Ideal-gas function with the V-P curve (ape Fig. 11). That is,

$$
P=p^{*}-12.06 \text { bars }
$$

ind

$$
\begin{aligned}
t & =\frac{1}{0.36} \ln \frac{36.7}{12.06-7.8} \\
& =5.98 \text { inutes }
\end{aligned}
$$




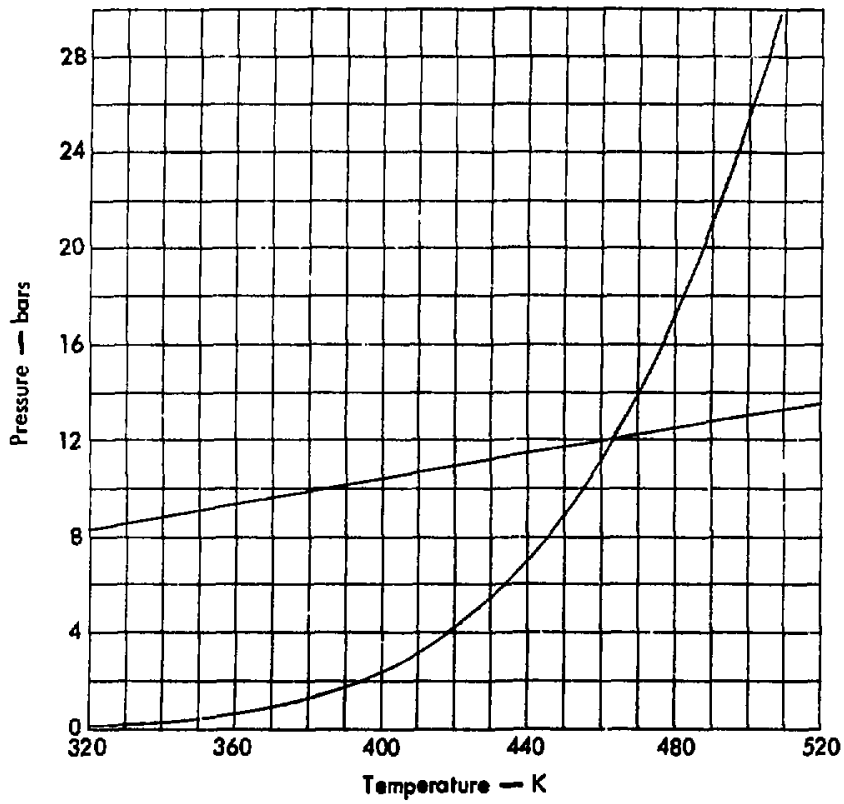

Fig. 11. Intersection of 0loen' original Idealmgas fit and the vapor preasure curve for water.

ThIs t tme agrees reasonably well with and

the estimate of 6.5 minutes that

$$
c_{v}=1.687 \times 10^{-3} \mathrm{~T}+5.52
$$

olsen made from the observed pressure data.

$A$ second calculation of this time hae been made using che modifted formation. The value $k_{2}$ la now a function of temperature since

$$
\begin{gathered}
h=0,0068(1+6,087 \\
\left.\times 10^{-4} \mathrm{~T}\right)
\end{gathered}
$$

are both functions of temperature. An excellent ftt for $c_{v}$ over the entire temperature range for condencing ctean is shown In Fig. 12.

The quantities $k_{1}$ and $k_{3}$ alno differ from olaen'a coeficlents becauke of the different formula uaed for cavity radiug. The condeneacion 


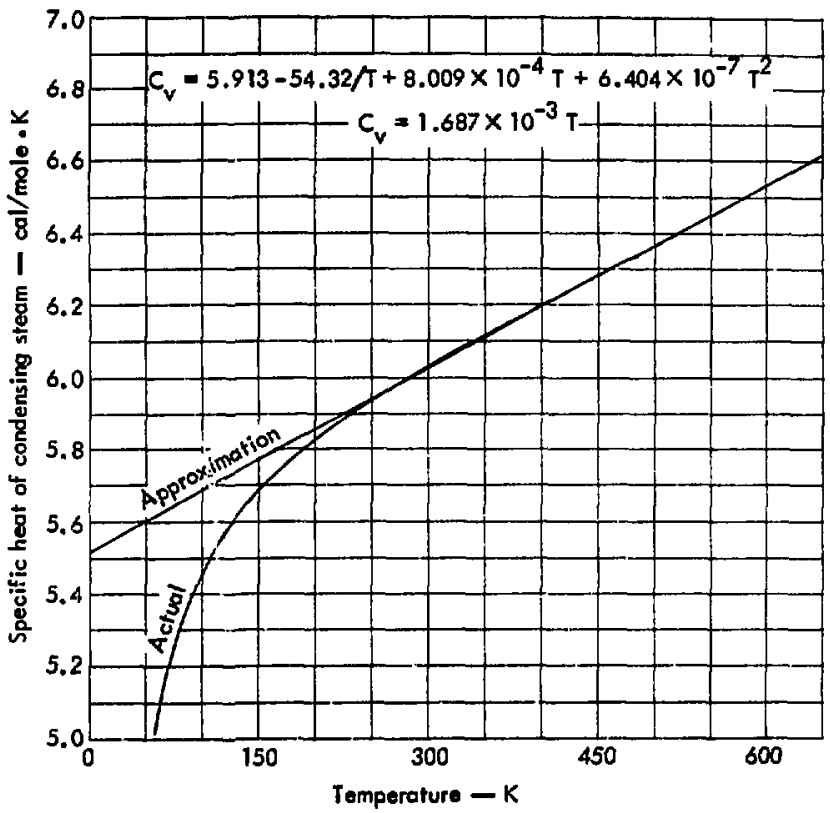

Fig. 12. Straight-1ine approsimation vs specific heat of condenging steam,

pressure and temperature $\mathrm{P}^{*}$ and $\mathrm{T}^{*}$ are calculated to be

$$
\text { P* }=9.64 \text { bara }
$$

and $T^{*}=453.6 \mathrm{~K}$.

The value of $t$ to aimilcrly arrived at as

$$
t *=7.76 \text { minutes. }
$$

This time of condensation can be observid (1n F1g. 7) as the point where the observed pressure begins to fall away from that calculated. 


\section{Calcultion of Time Duration and Heat Lost During Condensation}

The condensation of the cavity vepor is not an 1sothermal process because it is not isobaric. We assune the process is slow enough so that the water vapor remains in equilibrium with the condensing liquid. This "saturated" vapor must follow the vapor pressure curve as it condenses. Initially, heat is lost to the walls at a rate of

$$
\frac{\Delta q}{\Delta t}=h \star A(T *-T)
$$

where

$$
\begin{aligned}
& \frac{\Delta \mathrm{q}}{\Delta \mathrm{t}} \text { is expressed in } \mathrm{Ca} / \mathrm{sec} \\
& \mathrm{T}^{*} \text { - temperature at inciplent } \\
& \text { condensation }
\end{aligned}
$$

and $h^{*}=$ the heat transfer coefficient during condensation.

\section{olsen ${ }^{1}$ suggested "dropwise"} condensacion as a probable mode due to the value of h* (1.e., h* $-1.31 \mathrm{cal}$ ) $\left.\mathrm{cm}^{2} \cdot \mathrm{sec} \cdot \mathrm{K}\right)$ he inferred from his calculations on the observed data. However, upon reviowing these calculations we have arrived at a value of $h$ * lowsr by a factor of 20 (1.0.. h* $=0.07 \mathrm{cal} / \mathrm{cm}^{2} \cdot$ gec $\left.\cdot k\right)$ than originally computed. "Filisise" 6 condensation lo ryptfled by ralues of li* In enis range, agsuming heat r ransport to be dominated by convection.
The total hest lost throughout the entire condensation phase has to be less than $n_{0} \lambda_{p}$ where

$$
\begin{aligned}
n_{0}= & \text { original moles of vapor. } \\
\lambda_{p}= & \text { the latent heat of } \\
& \text { vaporization at the triple } \\
& \text { point }
\end{aligned}
$$

since the latent heat of the phase transformation is a maximum at the triple point (see F1g. 13). Thus, the minimum duration time of condensation can be estimated from

$$
\frac{{ }_{0} \lambda_{P}}{60 \Delta t}=h^{\star} A\left(T^{*}-T_{\infty}\right)
$$

$$
\Delta t=\frac{n_{0}{ }^{2}}{60 h \star_{A}\left(T^{*}-T_{\infty}\right)}
$$

where $\Delta t$ is expressed in minutes. For our example data this value comes out to be approximately 4.4 minutes.

The DCAVSTM code calculates this time more accurately by computing a running sum of the total heat lost at each time otep to prisuide an integraced maximum heat loss value,

$$
q_{\max }-\sum\left(\frac{\Delta q}{\Delta t}\right) \Delta t
$$

at

$$
T=T_{\infty}=300 R
$$

from which

$$
\Delta t=\frac{Q_{\max }}{60 h+A\left(T-T_{\infty}\right)}
$$


The code calculates this value to be approximate?y 3.8 minutes.

For the event we considered, condungation occurred at a calculated temperature of 453K. Using the latent heat of vaporization of water at that remperature (see Fig, 13) we can calculate the approximate heat loss by two other methods.
(1) If we assume the process $1 \mathrm{~g}$ 1sothermal with

$$
\lambda\left(T^{*}\right)=8661 \mathrm{cal} / \text { mole }
$$

and

$$
n_{0}=3.033 \times 10^{7} \text { moles of vapor }
$$

the latent heat evolved at that temperature is

$$
\begin{aligned}
& H_{1}= n_{0} \lambda(T *)=3.033 \times 10^{7} \times \\
& 8661-2.63 \times 10^{11} \mathrm{cal} .
\end{aligned}
$$

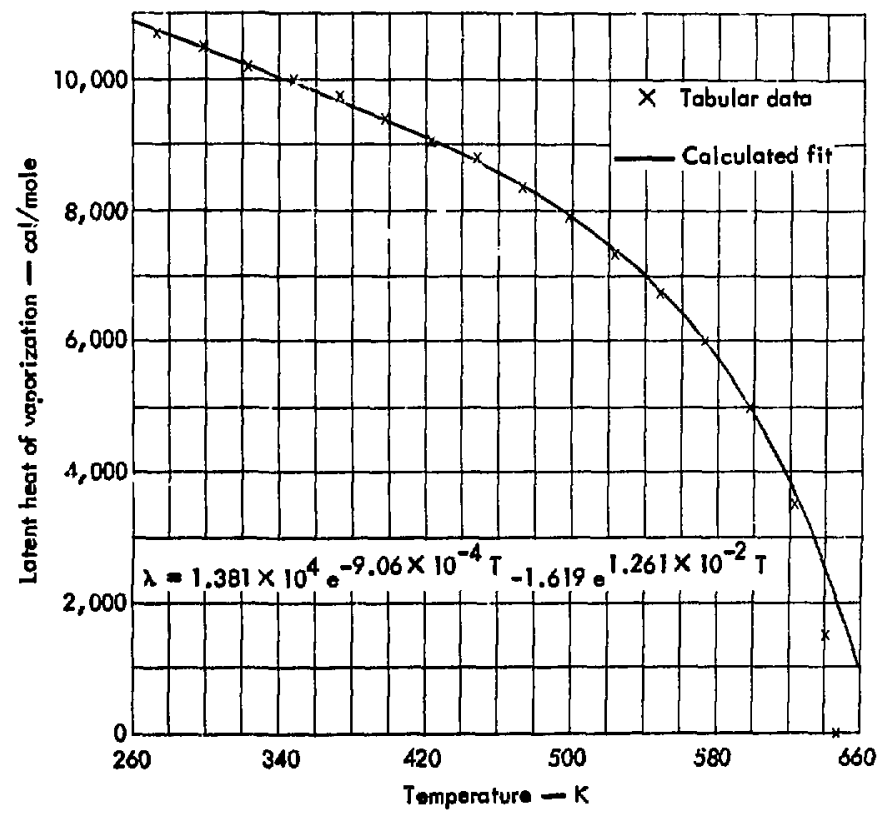

F18. 13. Exponential f1t to the latent heat of vaporization for water. 
The path traversed over the PVT surface for water is $A+B$ (see $F i g$. 14). The path from $B$ to $C$ is

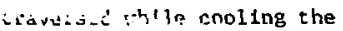
saturated water from $453 \mathrm{~K}$ r, $300 \mathrm{~K}$; it is

$$
\begin{aligned}
H_{2}= & n_{0} \Delta T c_{p}=3.033 \times 10^{7} \times \\
& 153 \times(1 \mathrm{cal} / \mathrm{g} \cdot \mathrm{K}) \\
= & 4.64 \times 10^{9} \mathrm{cal}
\end{aligned}
$$

where $1 \mathrm{cal} / \mathrm{g} \cdot \mathrm{K}$ is the spectfic heat of water.

Finally, the total heat lost is

$$
\begin{aligned}
Q & =H_{1}+H_{2} \\
& =2.68 \times 10^{11} \mathrm{cal} .
\end{aligned}
$$

(2) Use of standard mechanicalengineering "steam tables" is valid whether or not the process is

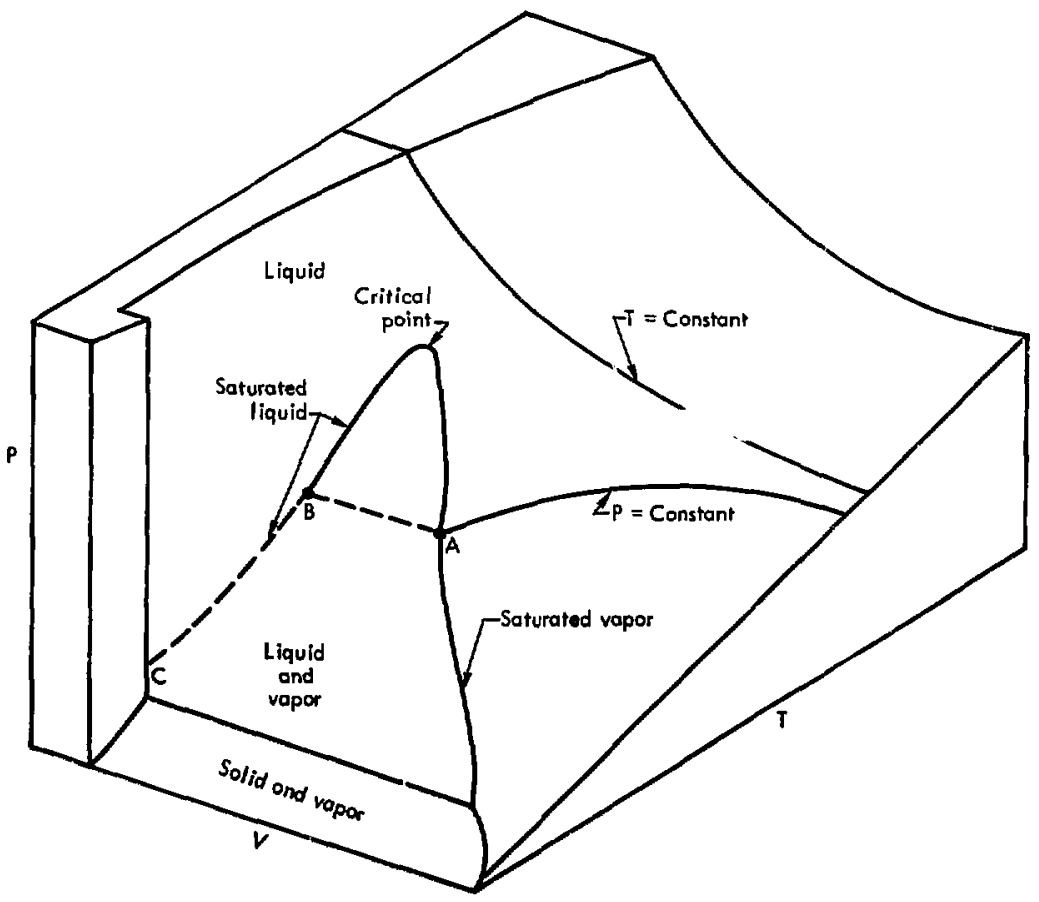

F1B. 14. PVT surface for water, showing poselble paths during condensation. 
1sotherial since Internal energy values are required only at the Initial and final states. At point $A\left(T^{*}=453 \mathrm{~K}\right.$ and $P^{\star}=9.64$ bars) the cavity is filled with saturated vapor. The specific internal energy of the saturated vapor is found to be

$$
u_{1}=11102.22 \mathrm{ca} 1 / \mathrm{mole} \text {. }
$$

After complete condensation,

$$
T_{\text {final }}=T_{\infty}=300 \mathrm{~K},
$$

and

$$
P_{\text {final }}=0.034 \text { bars. }
$$

The specific internal enargy of the saturated liquid is

$$
u_{f}=476.31 \mathrm{cal} / \text { mola. }
$$

Applying the first law of thermodynamics,

$$
Q-W=\Delta y
$$

where $W=0$ (since no work is being done by the system, 1.e., the gas in the cavity)

$$
\begin{aligned}
Q= & v_{f}-u_{1}=n_{0}\left(u_{f}-u_{f}\right) \\
Q= & -3.033 \times 10^{7} \\
& \times(11102.22-476.31) \\
Q= & -3.22 \times 10^{11} \mathrm{ca} .
\end{aligned}
$$

(The minus sign signifies that energy Is lost by the systen.)

The condensation code (DCAVSTM) calculated a total value of $Q=2.81$ $x 10^{11}$ calories for the example data. It is Interesting to note that this energy 1s somewhat less than $5 \%$ of the total device energy of $6.5 \times 10^{12}$ calories. A summary of all output results for the cavity calculation is given in Table 1 .

Table 1. Code-calculated results relating to $\mathrm{H}_{2} \mathrm{O}$ condensation for the example event

Time of Incipient condensation

Pressure at condensation

Temperature at condensation

Total heat lost durtng condengacton

Total cime of condenmation $\left(T \equiv T_{\infty}\right)$
7.76 minutes

9.64 bars

$453.6 \mathrm{~K}$

$2.81 \times 10^{11}$ calorjes

$6+3$ minutes 


\section{Calculation of the Pressure-Temperature History During Condensation}

The clapeyron-Claustus equation ${ }^{7}$ is applicable during condensation. It is obtained as

$$
\frac{\mathrm{d} P}{\mathrm{dT}}=\frac{\lambda}{\mathrm{T} \Delta \mathrm{V}}
$$

where

$$
\Delta v=v_{\text {gas }}-v_{\text {liquid }}
$$

This expression is the difference between sFicific volumes of the two phases present. Since vilquid is very small in comparison with the gas volume $v_{\text {gas }}$ and for a typtcal cavity of volume $V$, we may make the following approximation

$$
\Delta v \cong v_{\text {gas }} \approx \frac{v}{n}
$$

where

$$
\mathbf{n}=\text { number of moles of vapor }
$$

present. Thus, we may rewrite equation (34) as

$$
\frac{\mathrm{dP}}{\mathrm{dT}}=\frac{\lambda \pi}{\mathrm{TV}}
$$

which may be recogntzed as the slope of the vapor pressure curve at a given temperature. The number of moles of vipor is then calculable from this expresston as

$$
\mathbf{n}=\frac{\mathrm{TV}}{\lambda} \frac{\mathrm{dP}}{\mathrm{dT}} \text {. }
$$

Erom Eq. (20) we found that

$$
\frac{d y}{d T}=\frac{c_{1} c_{2}}{T_{2}} e^{-c_{2} / T} .
$$

In addition, $\lambda$ has been well fitted to the analytic exponential form (see FIg, 13):

$$
\lambda(T)=D_{1} e^{E_{1} T}+D_{2} e^{E_{2} T}
$$

where $\lambda(T)$ is expressed in cal/mole. The equation 35 becomes

$$
n(T)=\frac{V c_{1} c_{2} e^{-c_{2} / T}}{T\left(D_{1} e^{E_{1} T}+D_{2} e^{E_{2} T}\right)}
$$

where, for water vapor, the values of each of the fitting coeffictents are:

$$
\begin{aligned}
& c_{1}=3.32431 \times 10^{5} \\
& c_{2}=4.73976 \times 10^{3} \\
& D_{1}=1.381 \times 10^{4} \\
& E_{1}=-9.063 \times 10^{-4} \\
& D_{2}=-1.619 \\
& E_{2}=1.261 \times 10^{-2}
\end{aligned}
$$

and $n(T)$ is expressed in moles. The calculation of the pressure and temperature history during the phase change is performed by means of an Iterative calculation. Beginning with a time $t^{*}$ (time of inciplent condensation) and $n\left(t^{*}\right)$ (ortglnal moles of vapor) we calculate $\lambda\left(T^{*}\right)$ by use of $\mathrm{Eq}, 38$.

Then,

$$
P\left(T^{*}\right)=c_{1} e^{-c_{2} / T^{*}} \text {. }
$$


The heat-loss rate to the savity wall is

$$
q\left(t^{*}\right)=h{ }^{*} A\left(T^{*}-T_{\infty}\right) .
$$

We then increment the time to

$$
t_{1}=t^{*}+\Delta t
$$

and calculate

$$
n\left(t_{1}\right)=n\left(t^{*}\right)-\frac{g\left(t^{*}\right)}{\lambda\left(T^{*}\right)} \Delta t
$$

from which a new temperature $T_{1}$ is 1teratively calculated using the clapeyron-Clausius equation. The calculation then recycles back to the computation of $\lambda\left(\mathrm{T}_{1}\right), \mathrm{P}\left(\mathrm{T}_{1}\right)$, $q\left(t_{1}\right), t_{2}$ and $n\left(t_{2}\right)$, etc.

Figure 15 gives a comparison of the observed $c$ ita with the computed pressure history after condensation begins. Figure 16 shows the compartson over the entire range. Agreement here to fatrly good. F1gure 17 depicts the calculated temperature profile. A mark on the axis at 7.76 minutes denotes the calculated occurrence of inctpient condensation.

Although no $\mathrm{CO}_{2}$ was meagured for the event of the example data, we have neglected throughout this developweat the influence of Its presence (or an other noncondens1bles) in the cavity. Carbon dioxide remains a noncondensible during the
$\mathrm{H}_{2} \mathrm{a}$ condensation regime because of its relatively low bolling point of 194.7K and critical temperature of $304.28 \mathrm{~K}$. The ambient wall

temperatures hover in the nelghborhood of 300K. However, the $\mathrm{CO}_{2}$ does somewhat Increase the total pressure according to Dalton's law of partial pressures. Since virtually no $\mathrm{CO}_{2}$ would dissolve in the near bolling water puddle, the final cavity pressure should essentially become that of the resldual carbon dioxide. It is not clear what coupling effects significant concentrations of $\mathrm{CO}_{2}$ (> 5\%) would have on the cavity temperature during the $\mathrm{H}_{2} \mathrm{O}$ condensation phase since the process would then become a three-phase system. Whether the $\mathrm{CO}_{2}$ continues to cool independently according to the Newtonian prescription and to what extent it might retard the heat transfer to the walls remains to be investigated. The calculational technique described here is felt to provide a valid approximation for $\mathrm{CO}_{2}$ concentrations less than $5 \%$.

\footnotetext{
* Shot-point environments having greater than $5 \%$ by weight $\mathrm{CO}_{2}$ are generally deemed undesirable.
} 


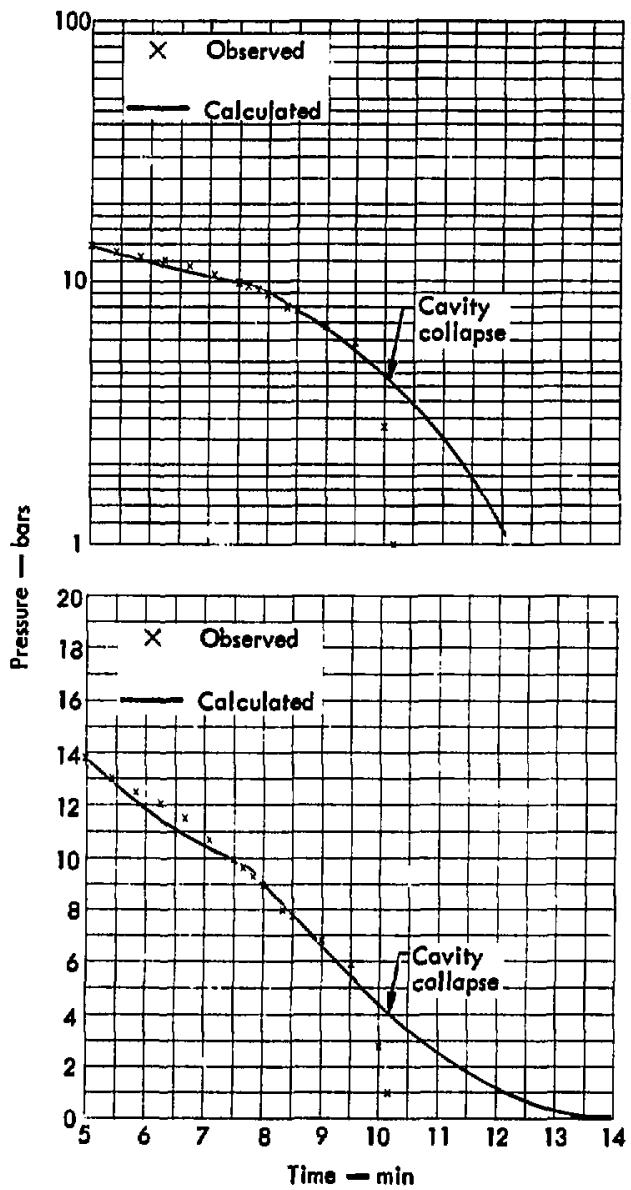

F1g. 15. Comparison of calculated condensation pressure history with the observed pressure, using Improved Newtonian equation. 


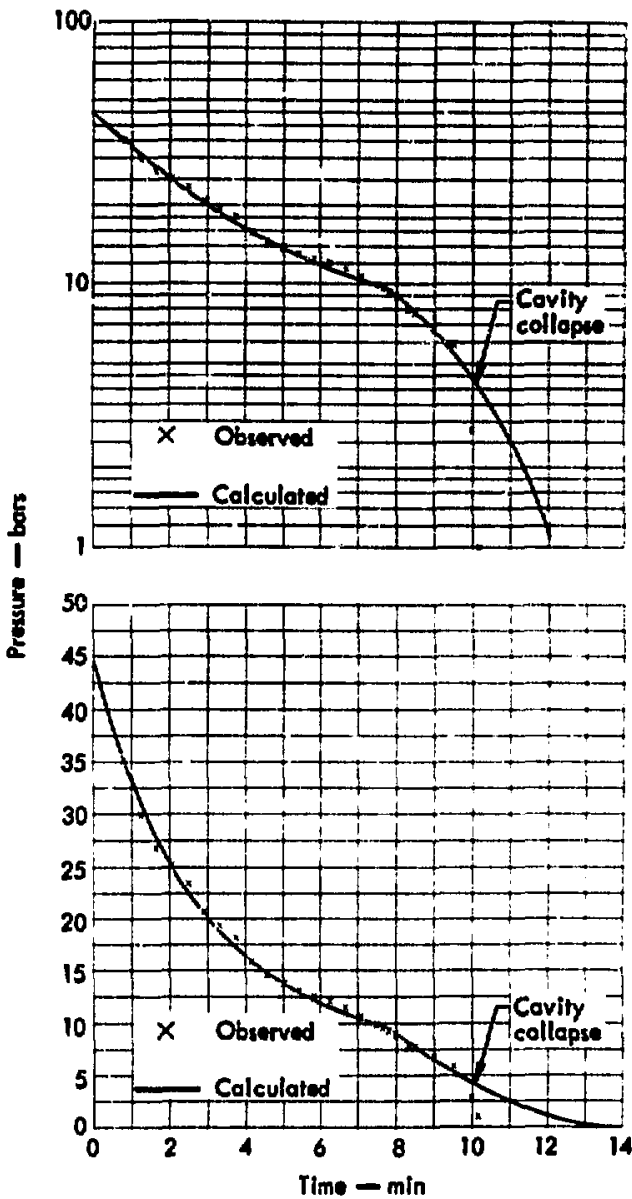

F18. 16. Comparison of entire calculeced preseure histary with the obseryed preseure, using improved Hewtonian equation. 


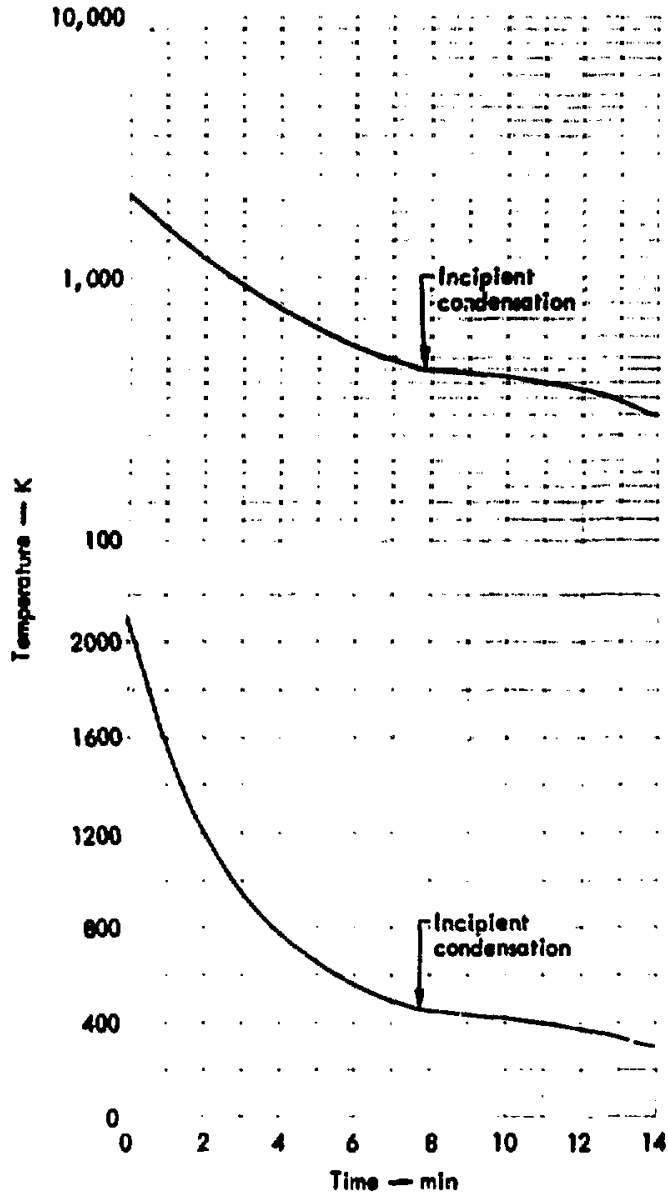

F1s. 17, Ageociated-temperature calculation uning Inproved Rewtonian equation. 


\section{Conclusion}

It has been demonstrated, at least for a particular event, that the application of the Clapeyron-Clausius equation may be used to describe the presaure and temperature decay during condensation of water vapor released by an underground nuclear event. The calculaced pressure has been found to approximute well the observed pressure during this che regime.

Unfortunately, due to difficulties uth survival of pressure transducers, we have had relatively few cavitypresture measureaents extending over the entire condeneation regime.
Accurate water-content analys1s and working-point density measurements together with the flelding of several redundant pressure sensors would greatly facllitate observation of the condensat ion history.

It might be worthwhile to conduct laboratory experiments to measure the convective heat coefficlent between saturated water vapor and a varfety of Nevada Test S1te (NTS) solls under a controlled temperature and pressure environment. This would shed light on the greatest factor of uncertainty in this type of calculation.

\section{Acknowledgement}

The author 18 gratefully Indebted to B. Hudson for helpful suggestions and Interesting discussions relating to the development of the model. 


\section{References}

1. C. W. Olsen, "Time HIstory of the Cavity Pressure and Teaperature Following a Nuclear Detonation In Alluvium," J. Geophyelcal Res. 72. 20 (1967).

2. C. W. Olsen, Pressure Decay in the Cavity Produced by a Contained Nuclear Explogion, Lawrence Livermore Laboratory, Internal Docunent UOPBA 70-84 (1970) (T1Cle U, report CRD). Readers outside the Luboratory who desire further information on LLL internal documente should address their Inquirles to the Technical Information Department, Lawrence Livermore Laboratory, Livermore, California, 94550.

3. E. McCauley, DCAVSTH, A Code for Cosputing the Cavity Gas Texperature History, Lawrence Livermore Laboratory, Internal Document ENA 75-40, Rev. 1 (1975).

4. G. H. Higgins and T. R. Butkovich, Effect of Water Content, Yield, Madium and Depth of Burst on Covicy Rad1i, Lawrence LIvermore Luboratory, Rept, UCRI-50203 (1967).

S. T. R. Butkovich, Gas Equation of State for Natural Material, Lawrence Livermore Labaratary, Rept. UCRL-14729 (1967).

6. H. N. KcAdams, Heat Transfer (McGraw-H111, New York, 1954).

7. H. J. Moore, Phygical Chemigtry. (Prentice-Hall, Newark, N.J., 1962). 


\section{Appandix: Derivation of the Newtoulan Cooling Equation}

TSOTHERAL HALL

A nonrigorous devulopment can be deacribed by a heat balance equat ion for the amount of heat given up co the walle by the cavity goe and the hest transferred by convection; nately

$$
p v_{v}, \frac{d T}{d t}=-h A\left(T-T_{\infty}\right) \text {. }
$$

If we define $m=\frac{h k}{o V c_{y}}$ and $n=o v$ then

$$
\frac{d T}{d t}=-n\left(T-T_{\infty}\right)
$$

Upon Integration

$$
\ln \frac{c_{1}}{T_{\infty}-T}=\text { at }
$$

where $c_{1}$ is an arbitrary constant. Inttal condtions are

Therer ie,

$$
\begin{aligned}
& t=0 \\
& T=T_{0}
\end{aligned}
$$

resultins, in

$$
c_{1}=T_{\infty}-T_{0}
$$

$$
\frac{T-T_{\infty}}{T_{0}-T_{\infty}}=e^{-\left(\frac{h A}{c_{v}^{n}}\right) t}
$$

NONISOTHERMAL WALL

If we allow the wall temperature ro rtse from $T_{\text {o }}$ to cone maxtmun value $T_{f}$ with exponential time

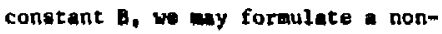
conatanc expresetion for the wall - enperature $T_{w}$ (ame $F I g \cdot A-1$ ),

$$
T_{w}=T_{\operatorname{wa11}}-T_{\infty}+T_{f}\left(1-e^{-B L}\right) .
$$

Then, weing

$$
p V e_{v} \frac{d T}{d t} n-h A\left(T-\tau_{u}\right) \text {. }
$$

and again defining

$$
=\frac{h A}{n V_{c_{y}}} \text {. }
$$

we obtain

$$
\frac{d T}{d t}=m\left(T_{\infty}+T_{f}\right)-m T_{f} e^{-B t}=\Delta T .
$$

- firet order differential equation whose solution we will simply state as

$$
T=\frac{c_{1} e^{-m t}+m^{2} T_{f} e^{-n t}}{m B-m^{2}}+
$$

whe $c_{1}$ is the constant of incesi ition at time $t=0$ and $T=T_{0}$. Whereupon

$$
\begin{gathered}
c_{1}=\left[m B-m^{2}\right]\left[T_{0}-\left(T_{\infty}+T_{f}\right)\right]- \\
m^{2} T_{f} .
\end{gathered}
$$

Equation $(A-1)$ now becomes

$$
\begin{gathered}
T=\frac{\left[m(B-m)\left(T_{0}-\left[T_{D}+T_{f}\right]\right)\right.}{m(B-m)} \\
\frac{\left.-m^{2} T_{f}\right]}{\left(T_{\infty}+T_{f}\right)} .
\end{gathered}
$$




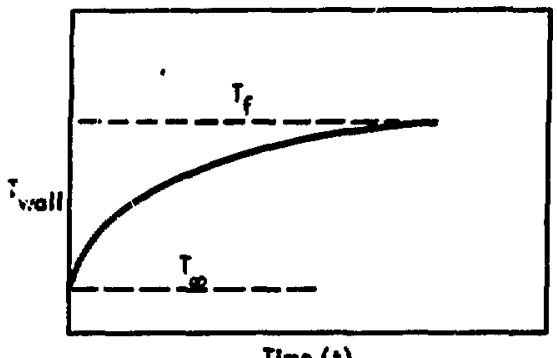

$\operatorname{Time}(t)$

F1g. A-1. Wall temparature vs tine.

Finally, we arrive at an expresalon for cavity tesperature with a non1sotheral wall:

$$
\begin{aligned}
T= & {\left[T_{0}-\left(T_{\infty}+\tau_{f}\right)-\frac{m T_{f}}{(B-m)}\right] e^{-n t} } \\
& +\frac{m T_{f}}{(B-m)} e^{-B t}+\left(T_{\infty}+T_{f}\right)
\end{aligned}
$$

for $B+m$.

It should he notwl, by the way, that 1f $B-0$ and $T_{f}-r_{\omega}$, the solution properly degenerates into the Isothoranl-wall solution. That 1t,

$$
\begin{aligned}
c_{1} & =-m^{2}\left[T_{0}-2 T_{\infty}\right]-m^{2} T_{\infty} \\
& =a^{2}\left[\tau_{\infty}-T_{0}\right] .
\end{aligned}
$$

Then, upon oubntitution 1nto Eq. (A-1) we arrive at the 1eothermal expreasion:

$$
T \cdot\left(T_{0}-T_{\infty}\right) e^{-a t}+T_{\infty} .
$$

